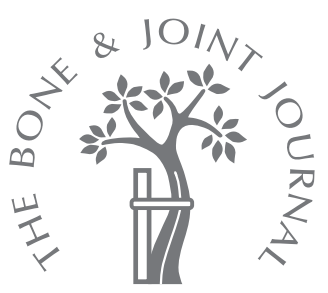

S. Ajami, G. W. Blunn, S. Lambert, S. Alexander, M. Foxall Smith, M. J. Coathup

From University College London, Middlesex, United Kingdom

- S. Ajami, BEng, MSc, PhD Student

G. W. Blunn, BSc, PhD,

Professor of Bioengineering

S. Lambert, BSc, FRCS, FRCS

Ed (Orth), Consultant

Orthopaedic Surgeon - S. Alexander, MBBS MSc

PhD FRCS, Consultant

Orthopaedic Surgeon

M. Foxall Smith, BSc,

Medical Student

M. J. Coathup, BSc,PhD,

Reader of Orthopaedic Implant

Fixation and Bone

Regeneration

University College London,

John Scales Centre for

Biomedical Engineering,

Institute of Orthopaedics and

Musculoskeletal Science, Roya

National Orthopaedic Hospital,

Brockley Hill, Stanmore,

Middlesex HA7 4LP, UK

Correspondence should be sent to Dr M. J. Coathup; e-mail:

m.coathup@ucl.ac.uk

(C)2016 The British Editorial

Society of Bone \& Joint

Surgery

doi:10.1302/0301-620X.98B4

$36600 \$ 2.00$

Bone Joint $J$

2016;98-B:504-11

Received 29 May 2015;

Accepted after revision 20

November 2015

- SHOULDER AND ELBOW

\title{
Histological evaluation of two designs of shoulder surface replacement implants
}

\author{
Aims \\ To assess the extent of osteointegration in two designs of shoulder resurfacing implants. \\ Bony integration to the Copeland cylindrical central stem design and the Epoca RH conical- \\ crown design were compared. \\ Patients and Methods \\ Implants retrieved from six patients in each group were pair-matched. Mean time to revision \\ surgery of Copeland implants was 37 months (standard deviation (SD) 23; 14 to 72) and \\ Epoca RH 38 months (SD 28; 12 to 84). The mean age of patients investigated was 66 years \\ (SD 4; 59 to 71) and 58 years (SD 17; 31 to 73) in the Copeland and Epoca RH groups \\ respectively. None of these implants were revised for loosening.
}

Results

Increased osteointegration was measured under the cup in the Copeland implant group with limited bone seen in direct contact with the central stem. Bone adjacent to the Epoca RH implants was more uniform.

Conclusion

This difference in the distribution of bone-implant contact and bone formation was attributed to the Epoca implant's conical crown, which is positioned in more dense peripheral bone. The use of a central stem may not be necessary provided there is adequate peripheral fixation within good quality humeral bone.

Take home message: Poor osteointegration of cementless surface replacement shoulder prosthesis may be improved by implant design.

Cite this article: Bone Joint J 2016;98-B:504-11.

Osteoarthritis is the most common reason for shoulder replacement surgery and is largely associated with ageing. ${ }^{1}$ The shoulder is the third most common joint to undergo arthroplasty and surgery has seen a nearly ten-fold increase in the last 25 years. $^{2}$ The National Joint Registry for England, Wales and Northern Ireland (NJR) reported that a total of 2225 shoulder arthroplasties were performed within a nine month period in 2012 . Of the 2225 procedures, 1202 were undertaken for osteoarthritis. ${ }^{3}$ Cementless surface replacement arthroplasty (CSRA) is increasingly being used to treat shoulder arthritis. Compared to stemmed total shoulder arthroplasties (TSA) these implants are designed to reproduce the individual's anatomy (diameter, radius of curvature, version) while preserving bone stock, making any subsequent revision easier. Good clinical outcomes at short- and mid-term follow-up of the Copeland implant (Biomet
Merck, Swindon, United Kingdom) has been reported. ${ }^{4,5}$ However, a recent clinical study reported a high revision rate where $22 \%$ of implants failed by 13 months after surgery and that failure was due to pain with 'overstuffing' of the joint, an un-resurfaced glenoid, or aseptic loosening of the humeral component. ${ }^{6}$ Overstuffing of the joint was stated to occur when the head of an implant protrudes excessively above the greater tuberosity resulting in increased tension on the rotator cuff and lengthening of the gleno-humeral offset. ${ }^{7,8}$ Altered joint reaction forces, component malposition, glenoid wear and insufficient bony support of the implant have been reported as factors that may contribute to aseptic loosening. ${ }^{1,9}$ Using finite element analysis Schmidutz et $\mathrm{al}^{10}$ reported stress shielding of bone in the sub cupola region adjacent to the Copeland design and predicted bone resorption in this region. Stress shielding is associated with 


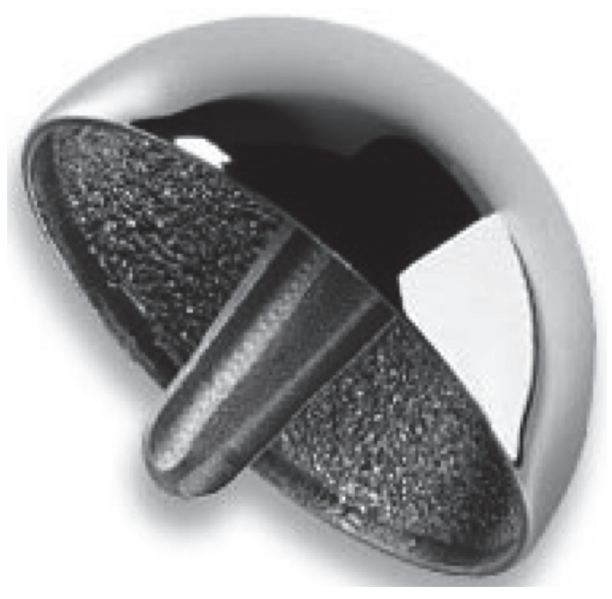

Fig. 1a

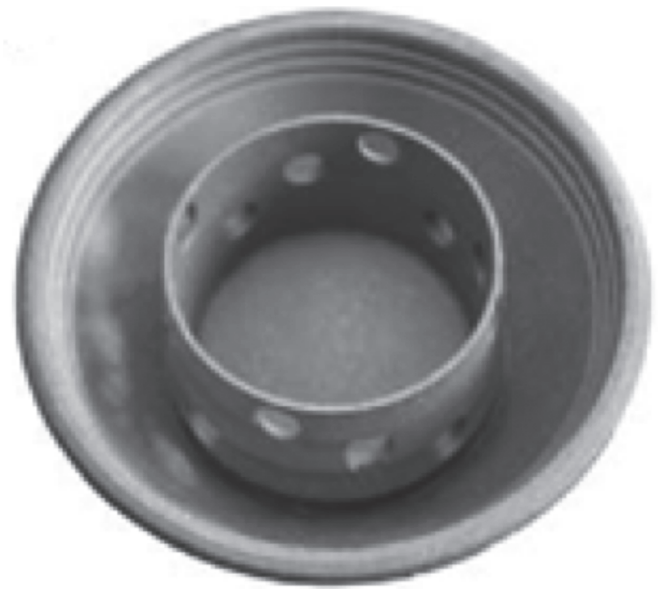

Fig. 1b

Photograph of the two types of shoulder resurfacing implants a) Copeland, and b) Epoca $\mathrm{RH}$.

Table I. Clinical data of 12 pair-matched patients with retrieved Copeland and Epoca RH humeral head resurfacing prostheses

\begin{tabular}{|c|c|c|c|c|c|c|c|}
\hline $\begin{array}{l}\text { Match } \\
\text { pair }\end{array}$ & $\begin{array}{l}\text { Implant } \\
\text { type }\end{array}$ & Age (yrs) & Gender & $\begin{array}{l}\text { Duration } \\
\text { in vivo (mths) }\end{array}$ & Side & Reason for replacement & Indication for failure \\
\hline \multirow[t]{2}{*}{1} & Epoca & 69 & $\mathrm{M}$ & 48 & Left & OA with significant pain & Pain, restricted ROM \\
\hline & Copeland & 70 & $\mathrm{~F}$ & 48 & Right & OA & Pain and limited ROM \\
\hline \multirow[t]{2}{*}{2} & Epoca & 65 & $\mathrm{~F}$ & 48 & Left & OA following an injury and instability & Rotator cuff failure \\
\hline & Copeland & 62 & $\mathrm{~F}$ & 48 & Left & OA & $\begin{array}{l}\text { Pain limited ROM axillary nerve } \\
\text { impingement }\end{array}$ \\
\hline \multirow[t]{2}{*}{3} & Epoca & 73 & $\mathrm{M}$ & 12 & Left & Rotator cuff tear & Glenoid erosion \\
\hline & Copeland & 65 & $\mathrm{~F}$ & 14 & Right & Rotator cuff tear & Glenoid wear and cuff tear \\
\hline \multirow[t]{2}{*}{4} & Epoca & 65 & $\mathrm{M}$ & 12 & Right & Cuff tear arthropathy & Instability \\
\hline & Copeland & 64 & $\mathrm{~F}$ & 16 & Left & Pain and $\mathrm{OA}$ & $\begin{array}{l}\text { Posterior and inferior glenoid } \\
\text { wear }\end{array}$ \\
\hline \multirow[t]{2}{*}{5} & Epoca & 31 & $\mathrm{~F}$ & 24 & Right & OA with instability & Persistent pain and instability \\
\hline & Copeland & 73 & $\mathrm{M}$ & 21 & Right & Pain and $\mathrm{OA}$ & $\begin{array}{l}\text { Glenoid wear and massive cuff } \\
\text { tear }\end{array}$ \\
\hline 6 & Epoca & 44 & $\mathrm{~F}$ & 84 & Right & Joint instability & Persistent pain and instability \\
\hline
\end{tabular}

redistribution of physiological load due to insertion of a stiffer metallic implant. ${ }^{11,12}$ Compared to the Copeland device, the fixation of the Epoca CSRA (Synthes, Oberdof, Switzerland) is associated with denser peripheral bone and has a conical crown design, which may affect bone ingrowth through stress distribution. In order to investigate whether design was a factor in implant fixation, the aim of this study was to quantify and compare bone-implant contact and bone area adjacent to these two designs. Our hypothesis was that the degree of osteointegration was a consequence of implant design.

\section{Materials and Methods}

Implant design and fixation. Both implant designs were manufactured from cobalt chrome with a spherical joint surface and inner surface plasma sprayed with a highly crystalline $(>85 \%)$ thin $(50 \mu \mathrm{m})$ hydroxyapatite coating. The Copeland implant consists of a central grooved and tapered stem, whereas the Epoca RH has no central stem but instead is stabilised by a hollow cylinder, which is referred to as a conical crown, positioned so that it is embedded within the circumferential trabecular bone of the humeral head (Fig. 1).

Study design. Following ethical approval, 25 Copeland and six Epoca RH cementless resurfacing shoulder implants were retrieved from patients at revision surgery. The patients' clinical records were reviewed and the following information collected: gender, age at the time of revision surgery, reason for primary CSRA, operated side, duration in vivo and reason for failure. A total of 12 patients were retrospectively pair-matched (six matched pairs) according to implant time in vivo, age and reason for surgery (Table I). Retrieved Copeland implants were obtained from four female and two male patients; and the six Epoca implants were obtained from three male and three female patients.

Histology. On retrieval, all implants with surrounding tissue were immersed in $4 \%$ paraformaldehyde solution at room temperature for seven days. Specimens were then pro- 


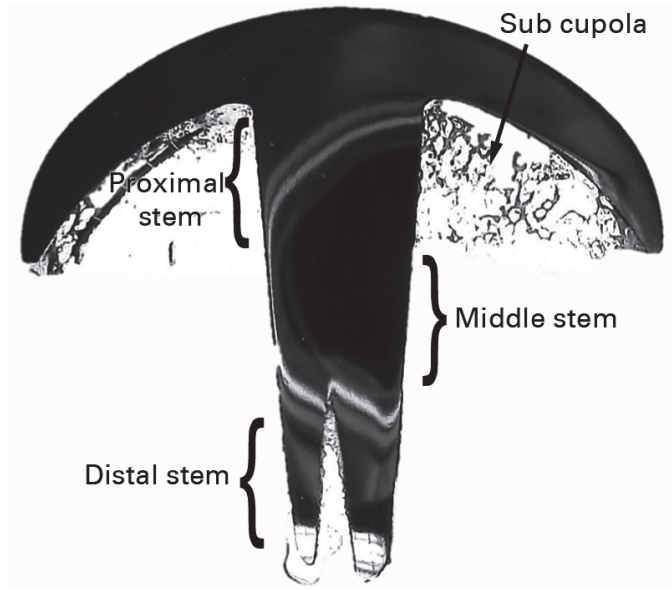

Fig. 2

Photomicrograph of a longitudinal section through a Copeland prosthesis showing the regions where measurements were taken.

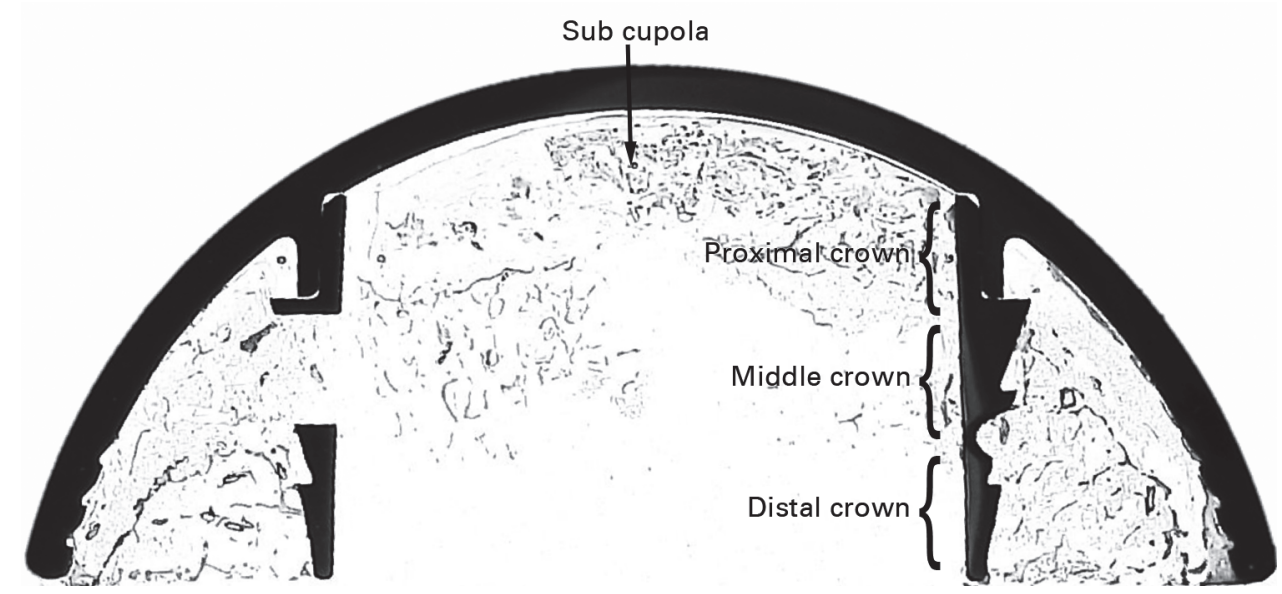

Fig. 3

Photomicrograph of a longitudinal section through an Epoca $\mathrm{RH}$ prosthesis showing regions where measurements were taken.

cessed for undecalcified hard tissue histology. Following dehydration in ascending concentrations of alcohol solution and defatting in chloroform, implants were embedded in hard grade acrylic resin (LR White, London Resin Company, Reading, United Kingdom). Longitudinal sections were prepared through the centre of each implant (orientation was unknown) using grinding and polishing techniques (EXAKT, Hamburg, Germany). During analysis, Copeland implants were divided into four regions of interest (ROI); under the shell, the proximal stem, mid-stem and distal stem (Fig. 2). Similar regions adjacent to the conical crown were identified in the Epoca RH implants (Fig. 3). All implants were initially examined using backscattered scanning electron microscopy (BSEM) (JEOL 3500 SEM, Tokyo, Japan). Thin sections (70 to $120 \mu \mathrm{m}$ ) where prepared and samples stained with toluidine blue and paragon, which stained soft tissue and bone respectively. Light microscopy and image analysis techniques (Axiovision 4.5,
Carl Zeiss, Jena, Germany) were used to quantify boneimplant contact and bone area within the ROI adjacent to the implant. Images spanning each implant were captured using a $5 \times$ objective lens and the percentage bone-implant contact calculated when the length of surface with direct bone attachment was divided into the total length of surface available for integration. Bone area measurements were calculated when five random areas within each ROI were image captured and 'free-hand' image analysis techniques used to select and quantify the area of bone. Boneimplant contact and bone area were then calculated as a mean from a set of images of each ROI and statistical comparisons were performed. Images were quantified by one assessor.

Statistical analysis. As the numbers were small, a normality test (Shapiro-Wilk) was carried out which showed that the data was non-parametric for regions in each implant group, and parametric when all regions were combined and the 


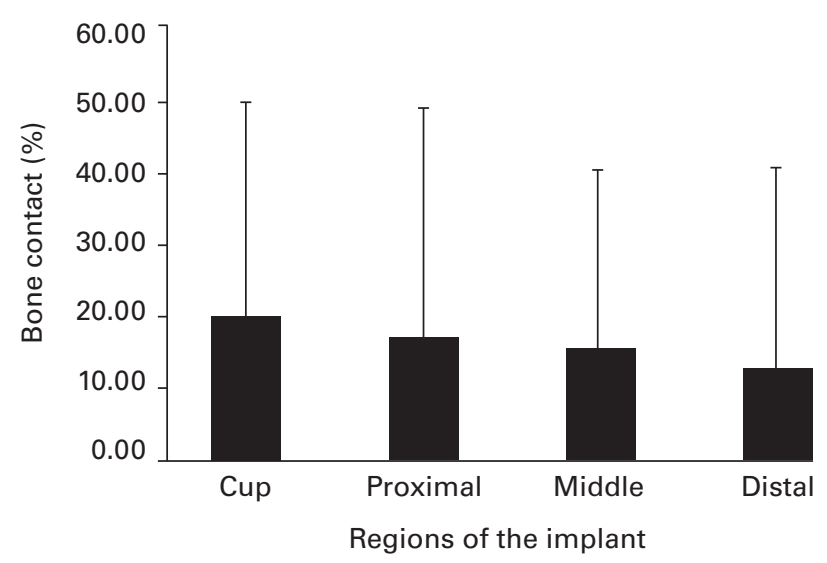

Fig. 4

Graph showing mean percentage of bone contact adjacent to the Copeland prosthesis by region of interest. Error bars indicate standard deviation.

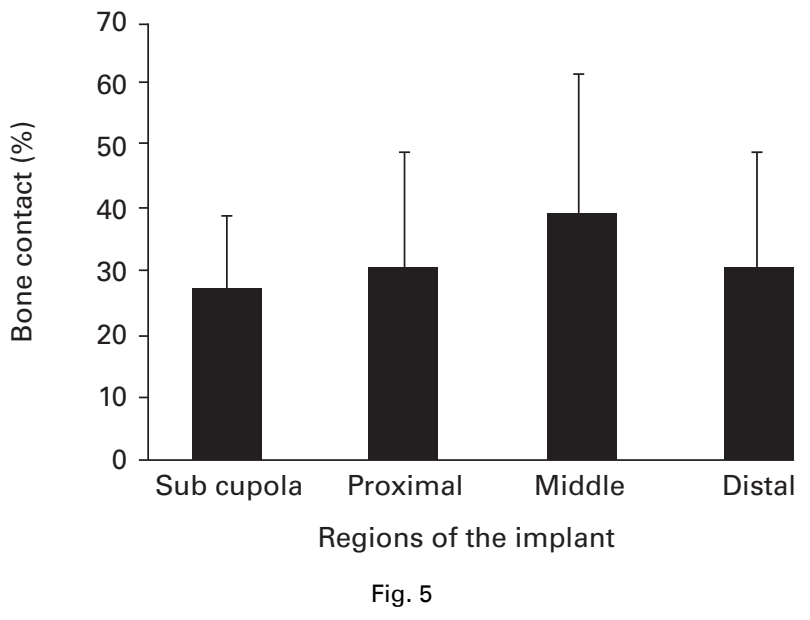

Graph showing mean percentage of bone contact adjacent to the Epoca $\mathrm{RH}$ prosthesis by region of interest. Error bars indicate standard deviation. two implant types compared. To determine significant differences between regions and implant type a Mann Whitney-U test was used where the data were non-parametric and a $t$-test for parametric data. These tests were done on all retrievals irrespective of time in vivo and reasonsfor failure. Spearman's rank correlation coefficient was used to assess whether there was a correlation between boneimplant contact and bone area, patient age and duration in vivo. Statistical significance was assumed for all $\mathrm{p}$-values $<0.05$. All measurements were reported as a mean with standard deviation (SD).

\section{Results}

Scanning electron microscopy. Qualitative examination of the Copeland implants showed that most bone-implant contact was observed in the area immediately beneath the cup. This was followed by the proximal, middle and distal regions of the stem in decreasing order. However, in comparison, bone-implant contact adjacent to Epoca $\mathrm{RH}$ implants appeared to be more uniformly distributed over the surface of the implant. In both implant groups, the amount of bone-implant contact seen varied between patients, but in all cases the bone layer present was thin. The trabecular connections and bone stock in the Copeland implants were mainly found in the cup region and was limited around the stem, whereas with the Epoca design it was more evenly distributed in regions connected to both cup and crown region of the implant. Variation was also seen where some patients had greater bone on one side of the cup compared with the opposite side, or one side of the stem compared with the other.

Bone-implant contact - sub-cupola region. Results showed a mean total bone-in-contact (BIC) of 19.92\% (SD 29.71; 9.75 to 33.41), in the sub cupola region of Copeland implants and a mean BIC of $26.10 \%$ (SD 10.50; 16.35 to 37.24 ) was measured in the sub-cupola region of Epoca $\mathrm{RH}$ implants. No significant difference between the two groups was found ( $\mathrm{p}=0.38$, independent samples $t$-test).

Bone-implant contact - stem. Mean BIC adjacent to Copeland implants in the proximal, $17.63 \%$ (SD 31.26; 2.31 to $39.84 \mathrm{p}=0.04$ ), mid $15.97 \%$ (SD 24.63; 5.08 to 29.34 , $\mathrm{p}=0.04$ ) and distal 13.47 (SD 27.14; 0.00 to 28.61, $\mathrm{p}=0.001$ regions of the stem was significantly decreased when compared with the sub-cupola region (Fig. 4). Significantly increased BIC was measured when the proximal $(\mathrm{p}=0.01)$ and mid $(\mathrm{p}=0.03)$ regions were compared with the distal region of the stem. No other significant differences were found. A Mann Whitney-U test was used to determine significant differences between regions.

In the Epoca RH group, the results showed no significant differences in the mean BIC when the sub-cupola region $26.10 \%$ (SD $10.50 ; 16.35$ to 37.24 ), was compared with the proximal $31.15 \%$ (SD $16.56 ; 12.43$ to $58.97 \%$, p $=0.818$ ), $\operatorname{mid} 39.40 \%$ (SD $56.40 ; 10.00$ to 66.40$), \mathrm{p}=0.485$ ) and distal $30.76 \%$ (SD 16.24; 11.64 to $51.91, \mathrm{p}=0.937$ ) regions of the conical cylinder (Fig. 5). An independent samples $t$-test was used to examine differences.

When all regions were combined and the two implant types compared, results showed that decreased mean BIC was found adjacent to the Copeland implants $16.84 \%$ (SD 10.40; 7.40 to 31.69 ) when compared with the implants in the Epoca RH group $31.85 \%$ (SD 16.43\%; 16.97 to 44.58$)$. However, this difference was not significant $(\mathrm{p}=0.056)$. An independent sample $t$-test was used to determine significant differences.

Bone area - sub-cupola region. In the sub-cupola region the mean bone area adjacent to the Copeland implant was $0.17 \mathrm{~mm}^{2}$ (SD $0.14 ; 0.03$ to 0.42 ) in contrast to the Epoca RH implants for which the mean bone contact area was $0.26 \mathrm{~mm}^{2}$ (SD $0.23 ; 0.14$ to 0.28 ). However this difference was not statistically significant $(\mathrm{p}=0.13$, independent samples $t$-test). 


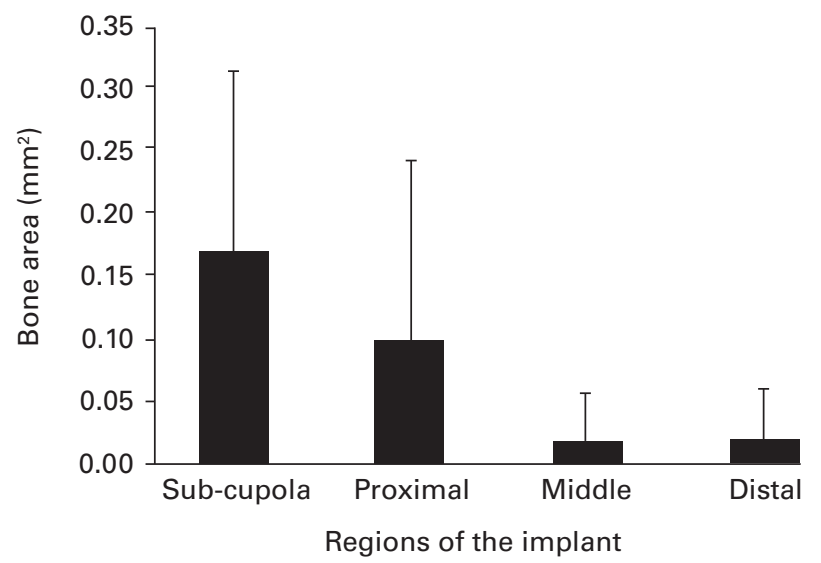

Fig. 6

Graph showing mean bone area adjacent to the Copeland prosthesis by region of interest. Error bars indicate standard deviation.

Bone area - stem. In the Copeland group, decreased mean bone area was measured in the proximal $\left(0.10 \mathrm{~mm}^{2}\right.$, SD $0.13 ; 0.01$ to $0.35, \mathrm{p}=0.18)$, mid $\left(0.02 \mathrm{~mm}^{2}\right.$, SD 0.04 ; 0.00 to $\left.0.11^{\prime} \mathrm{p}=0.041\right)$ and distal $\left(0.02 \mathrm{~mm}^{2}\right.$, SD $0.05 ; 0.00$ to $0.12, \mathrm{p}=0.01)$ zones of the stem when compared with bone area measured in the sub-cupola region (Fig. 6). However, no significant differences were found when each of the regions was compared. A Mann Whitney-U test was used to determine significant differences between regions.

In the Epoca RH group, reduced mean bone area was also measured in proximal $\left(0.18 \mathrm{~mm}^{2}\right.$, SD 0.07 ; 0.14 to $0.38 \mathrm{~mm}, \mathrm{p}=0.13)$, mid $\left(0.12 \mathrm{~mm}^{2}\right.$, SD $0.08 ; 0.02$ to $0.24, \mathrm{p}=0.04)$ and distal $\left(0.09 \mathrm{~mm}^{2}, \mathrm{SD} 0.04 ; 0.03\right.$ to $0.14, p=0.002$ ) regions adjacent to the conical crown when compared to the sub-cupola region (Fig. 7). Significantly increased bone area was measured in the sub-cupola region when compared with the mid and distal regions of the crown, and also when the proximal region of the crown was compared with the distal region $(p=0.04)$. An independent samples $t$-test was used to determine significant differences.

When all regions were combined and the two implant types compared, results showed decreased mean bone area adjacent to the Copeland implants $\left(0.08 \mathrm{~mm}^{2}\right.$, SD 0.06) compared with that measured adjacent to the Epoca $\mathrm{RH}$ implants $\left(0.16 \mathrm{~mm}^{2}\right.$, SD 0.12$)$ but this difference was found not statistically significant using a Mann Whitney-U test $(\mathrm{p}=0.065)$.

Correlation analysis. In the Copeland group and when the results for all implants and regions were combined, no significant correlation $(\mathrm{r}=-0.20, \mathrm{p}=0.70)$ was found when mean bone-implant contact and mean bone area were analysed. In addition, no correlation $(\mathrm{r}=0.26, \mathrm{p}=0.61)$ was found when bone area in the sub-cupola region and implant duration in vivo were analysed.

In the Epoca RH group, a significant correlation was found between mean bone-implant contact and duration in vivo, with a gradual increase in bone-implant contact over

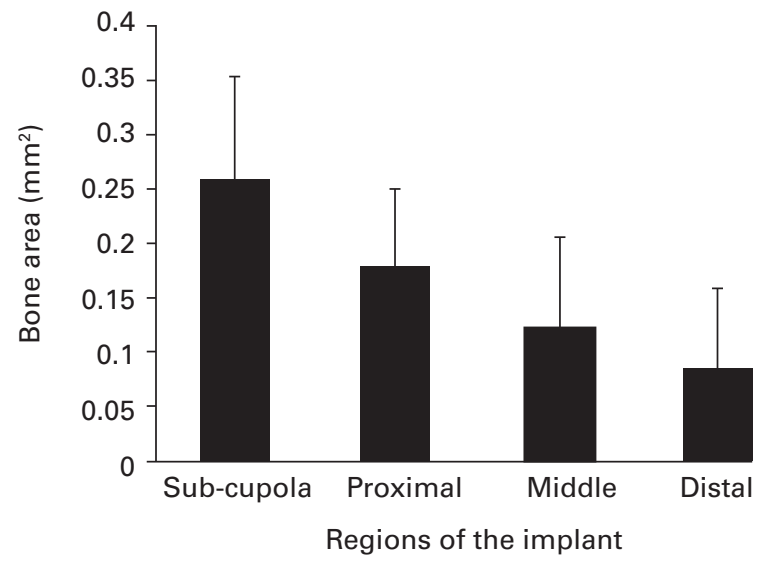

Fig. 7

Graph showing mean bone area adjacent to the Epoca $\mathrm{RH}$ prosthesis by region of interest. Error bars indicate standard deviation.

time $(\mathrm{r}=0.833, \mathrm{p}=0.020)$. When the results for all implants and regions were combined, no significant correlation $(\mathrm{r}=0.31, \mathrm{p}=0.54)$ was found when mean boneimplant contact and mean bone area were analysed. No significant associations in BIC were found when mean boneimplant contact and age $(\mathrm{r}=-0.48, \mathrm{p}=0.32)$; mean bone area and age $(\mathrm{r}=0.31, \mathrm{p}=0.54)$; and mean bone area and time in vivo $(\mathrm{r}=0.61, \mathrm{p}=0.19)$ were analysed.

\section{Discussion}

The long-term success of joint replacement surgery is dependent on many factors, including successful osteointegration. ${ }^{13}$ Stress shielding in hip resurfacing arthroplasty is due to load transfer by the stem causing non-physiological strain in the bone leading to proximal bone resorption. ${ }^{14,15}$ However, it must be considered that forces acting on the shoulder are different to those in the hip. Bone density in the humeral head is less than that of the femoral head and the orientation of trabeculae is also different. ${ }^{16}$ Both qualitative and quantitative analysis of the retrieved implants in our study showed reduced or no bone adjacent to the stem of Copeland prostheses. This may be associated with the size and positioning of the implant stem in the humeral head. The conical crown in Epoca RH implants is positioned in more dense bone, as it is located more peripherally than the central stem of the Copeland device. There is a decrease in bone density in the humeral head from superiorly to inferiorly and from posteriorly to anteriorly. ${ }^{17}$ The most superior and medial part of the humeral head was shown to possess the highest bone mass. ${ }^{18}$ In addition bone density is greatest at the periphery of the humeral head and becomes less dense centrally. Satioh et $\mathrm{al}^{19}$ showed the proximal part of the humeral head had the greatest amount of bone mineral, with the humeral neck having only approximately one half of the bone mineral density of the head. Additionally, the cancellous bone of the neck demonstrated only one third of the mechanical strength of the humeral head following indention testing. We have shown 


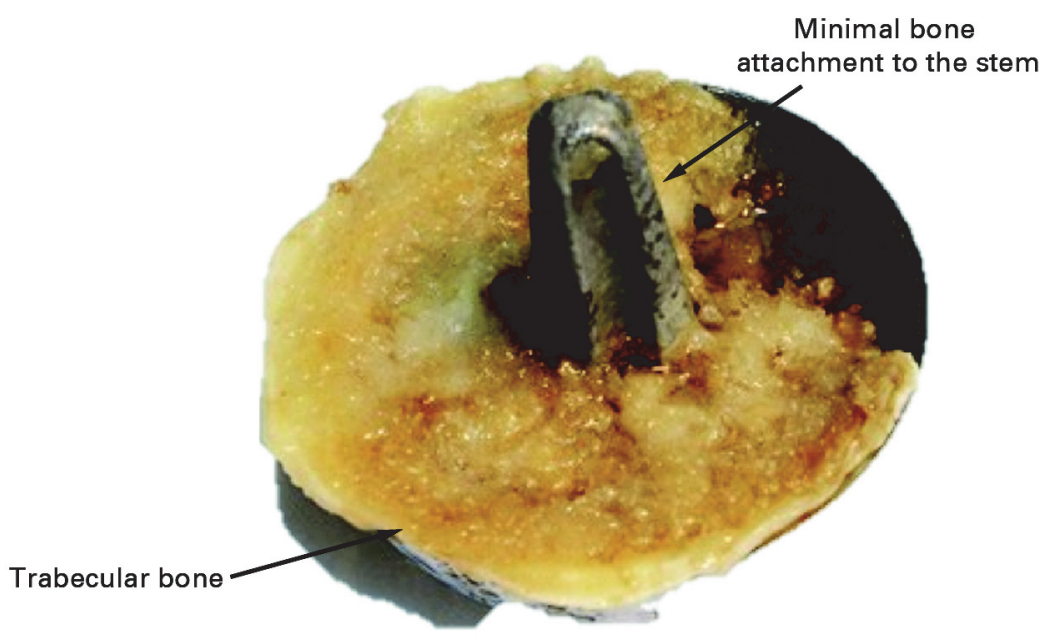

Fig. 8a

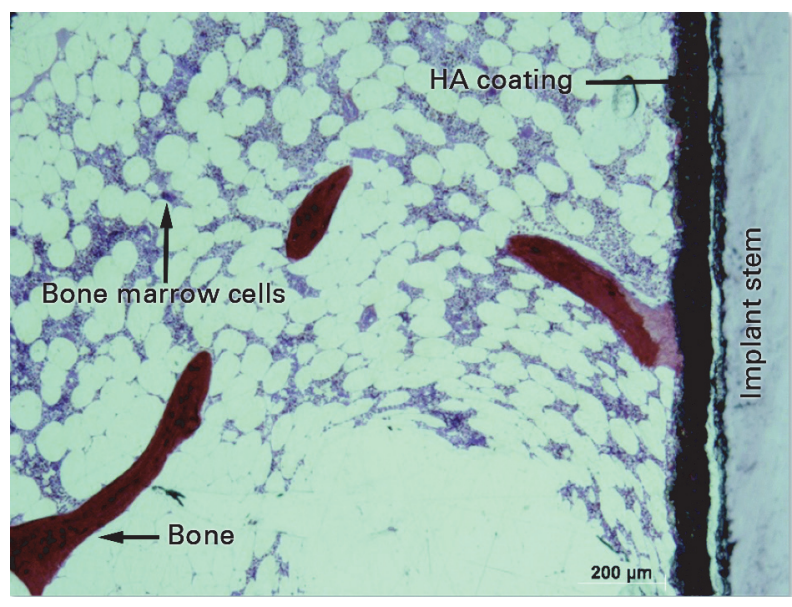

Fig. $8 \mathrm{~b}$

a) A photograph of a retrieved Copeland implant (duration in vivo, 16 months) following retrieval showing trabecular bone formation within the sub cupola region with no bone adjacent to the stem. b) A photomicrograph showing minimal bone contact to the stem surface.

that the position of the stem in the Copeland and the conical crown in the Epoca RH devices significantly affected the amount and distribution of bone contact and bone formation. Epoca RH implants demonstrated uniform bone growth and bone contact over the entire surface whereas the Copeland implants showed most bone in growth in sub cupola region (Figs 8 and 9).

Our results are in contrast to a recently published Finite Element Analysis (FEA) study on the CRSA by Schmidutz et $\mathrm{al}^{10}$ in which the predicted increased compressive strain adjacent to the stem led to bone apposition. Three-dimensional FEA models of hip resurfacing arthroplasty also described bone loss and reduced stress under the femoral component due to increased stress around the stem and bone formation. ${ }^{15,20-23}$ Orr et al, ${ }^{24}$ using two-dimensional finite element models for hip resurfacing, reported that stress shielding occurred underneath the metal femoral component, resulting in lower bone density in the femoral head, and that the addition of a central femoral stem caused bone hypertrophy adjacent to the stem. In our study, bone apposition for both implants was observed adjacent to the sub cupola region, which may indicate proximal stress transfer. For the Copeland implant, stress transfer from the stem may be limited because of the poor quality bone in this region. Bone-implant contact was more uniform for the Epoca RH implant with no significant differences in boneimplant contact observed between the different implant regions. This may be attributed to the design and increased surface area of the crown leading to more beneficial stress distribution. ${ }^{10}$ In contrast to the Copeland implant, quantitative assessment showed the Epoca RH design to enhance osteoconductivity of bone on the HA coated surface. 


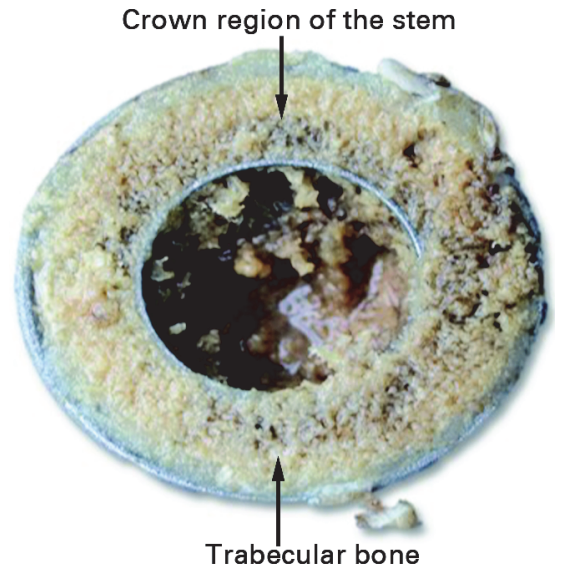

Fig. 9a

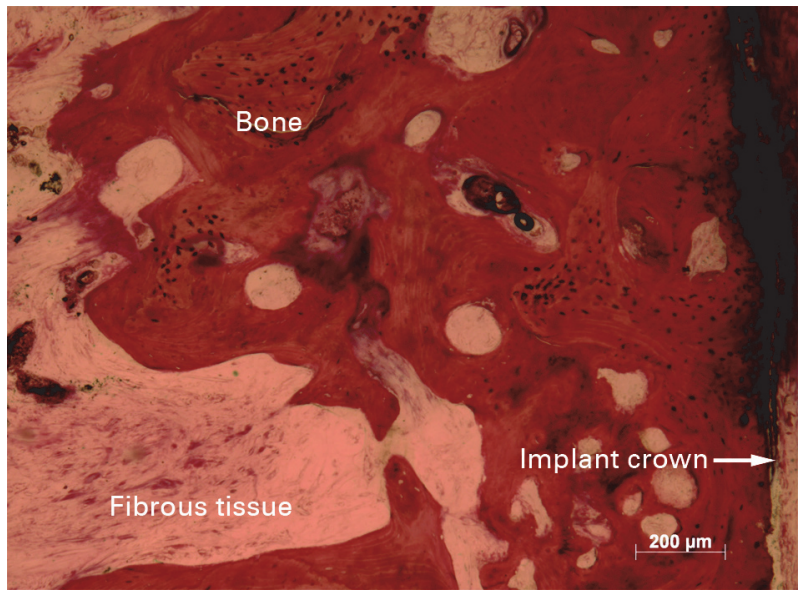

Fig. 9b

a) A photograph of a retrieved Epoca $\mathrm{RH}$ implant (duration in vivo, 84 months) following retrieval showing trabecular bone within the sub cupola region and surrounding the conical crown b) A photomicrograph showing mature lamellar bone in direct contact to the implant surface. HA, hydroxyapatite.

One of the prerequisites to accomplish optimal bone fixation is primary implant stability at the time of surgery. Once primary stability is achieved as a result of pressfitting, bone remodelling will be initiated providing secondary stability. ${ }^{25,26}$ Implant design and surgical technique are two important elements in establishing effective initial fixation as it determines the relative movement between the implant surface and host bone. ${ }^{27,28}$ Formation of fibrous tissue at the interface adjacent to the Copeland implants, suggests insufficient primary stability. One of the reasons that Epoca RH implant showed more contact may be due to primary stability associated with larger implant area available for bone ingrowth which is positioned in denser cancellous bone.

Kasten et $\mathrm{al}^{29}$ reported that the location of a bone defect and type of implant stabilisation have a high impact on primary stability of CRSA. Their study investigated micromotion of two CSRA designs ( $\mathrm{n}=5$ ), namely the Epoca RH (Synthes GmbH, Oberdorf, Switzerland) and Aequalis (Tornier SAS, Saint-Ismier Cedex, France) with a central stem implanted with bone defects varying from $0 \%$ to $37 \%$ of humeral head volume. Results showed that Epoca RH implants had a decreased micromotion $(<150 \mu \mathrm{m})$ with all sizes of defect compared with the Aequalis design. ${ }^{29}$ The initial stability of the conical crown design may be associated with enhanced longer term bone formation compared with the stem design investigated in our study.

Our study had several limitations. Firstly, it was a retrospective analysis in a small number of matched patients. Secondly, the orientation of the implants was unknown.

In summary, in this study the osteointegration of two different designs of shoulder resurfacing replacements has been investigated. All of the implants had been revised, though none for loosening. Comparison of the two designs suggested that implant design affected bone attachment and distribution around the implants and that osteointegration of CRSA may be dependent on implant design.
Therefore, this study suggests that the use of a central stem may not be necessary provided there is adequate peripheral fixation within good quality humeral bone.

\section{Author contributions:}

S. Ajami: Writing Paper, Data Collection, Data Analysis.

G. W. Blunn: Study Design, Data Interpretation, Writing Paper.

S. Lambert: Performed Surgeries, Data Interpretation, Reviewed Paper Drafts. S. Alexander: Data Interpretation, Reviewed Paper Drafts.

M. Foxall Smith: Data Collection, Data Analysis.

M. J. Coathup: Study Design, Data Interpretation, Writing Paper.

No benefits in any form have been received or will be received from a commercial party related directly or indirectly to the subject of this article.

This article was primary edited by G. Scott.

\section{References}

1. Grayson CW, Decker RC. Total joint arthroplasty for persons with osteoarthritis. PM R 2012;4(5 suppl):S97-S103.

2. Adams JE, Sperling JW, Hoskin TL, Melton LJ III, Cofield RH. Shoulder arthroplasty in Olmsted County, Minnesota, 1976-2000: a population-based study. J Shoulder Elbow Surg 2006;15:50-55.

3. No authors listed National Joint Registry for England, Wales and Northern Ireland, 10th Annual Report. 2012. http://www.njrcentre.org.uk/njrcentre/Portals/0/Documents/England/Reports/10th_annual_report/

NJR\%2010th\%20Annual\%20Report\%202013\%20B.pdf (date last accessed 23 February 2016).

4. Levy 0, Copeland SA. Cementless surface replacement arthroplasty (Copeland CSRA) for osteoarthritis of the shoulder. J Shoulder Elbow Surg 2004;13:266-271.

5. Al-Hadithy N, Domos P, Sewell MD, et al. Cementless surface replacement arthroplasty of the shoulder for osteoarthritis: results of fifty Mark III Copeland prosthesis from an independent center with four-year mean follow-up. J Shoulder Elbow Surg 2012;21:1776-1781.

6. Norris TR, Iannotti JP. Functional outcome after shoulder arthroplasty for primary osteoarthritis: a multicenter study. J Shoulder Elbow Surg 2002;11:130-135.

7. Mechlenburg I, Amstrup A, Klebe T, et al. The Copeland resurfacing humeral head implant does not restore humeral head anatomy. A retrospective study. Arch Orthop Trauma Surg 2013;133:615-619.

8. Merolla G, Di Pietto F, Romano S, et al. Radiographic analysis of shoulder anatomical arthroplasty. Eur J Radio/ 2008;68:159-169.

9. Cil A, Veillette CJ, Sanchez-Sotelo J, et al. Revision of the humeral component for aseptic loosening in arthroplasty of the shoulder. J Bone Joint Surg [Br] 2009;91B:75-81

10. Schmidutz F, Agarwal Y, Müller PE, et al. Stress-shielding induced bone remodeling in cementless shoulder resurfacing arthroplasty: a finite element analysis and in vivo results. J Biomech 2014;47:3509-3516.

11. Niinomi M, Nakai M. Titanium-Based Biomaterials for Preventing Stress Shielding between Implant Devices and Bone. Int J Biomater 2011; 2011:836587. 
12. Nagels J, Stokdijk M, Rozing PM. Stress shielding and bone resorption in shoulder arthroplasty. J Shoulder Elbow Surg 2003;12:35-39.

13. Bauer TW, Schils J. The pathology of total joint arthroplasty. I. Mechanisms of implant fixation. Skeletal Radiol 1999;28:423-432.

14. Ong KL, Kurtz SM, Manley MT, et al. Biomechanics of the Birmingham hip resurfacing arthroplasty. J Bone Joint Surg [Br] 2006;88-B:1110-1115.

15. Gupta S, New AMR, Taylor M. Bone remodelling inside a cemented resurfaced femoral head. Clin Biomech (Bristol, Avon) 2006;21:594-602.

16. Saitoh S, Nakatsuchi Y. Osteoporosis of the proximal humerus: comparison of bone-mineral density and mechanical strength with the proximal femur. J Shoulder Elbow Surg 1993;2:78-84

17. Twiss T. Nonoperative Treatment of Proximal Humerus Fractures. In: Crosby LA Neviaser RJ, eds. Proximal Humerus Fractures: Evaluation and Management Springer International Publishing, Cham; 2015:23-41.

18. Barvencik F, Gebauer M, Beil FT, et al. Age- and sex-related changes of humera head microarchitecture: histomorphometric analysis of 60 human specimens. J Orthop Res 2010;28:18-26.

19. Saitoh S, Nakatsuchi Y, Latta L, Milne E. Distribution of bone mineral density and bone strength of the proximal humerus. J Shoulder Elbow Surg 1994;3:234-242.

20. Watanabe Y, Shiba N, Matsuo S, et al. Biomechanical study of the resurfacing hip arthroplasty: finite element analysis of the femoral component. J Arthroplasty 2000;15:505-511.

21. Vena P, Verdonschot N, Contro R, Huiskes R. Sensitivity analysis and optima shape design for bone-prosthesis interfaces in a femoral head surface replacement. Comput Methods Biomech Biomed Engin 2000;3:245-256.
22. Cristofolini L, Juszczyk M, Taddei F, et al. Stress shielding and stress concentration of contemporary epiphyseal hip prostheses. Proc Inst Mech Eng H 2009;223:27-

23. Bryan R, Nair PB, Taylor M. Influence of femur size and morphology on load transfer in the resurfaced femoral head: A large scale, multi-subject finite element study. J Biomech 2012;45:1952-1958.

24. Orr TE, Beaupré GS, Carter DR, Schurman DJ. Computer predictions of bone remodeling around porous-coated implants. J Arthroplasty 1990;5:191-200.

25. Lioubavina-Hack N, Lang NP, Karring T. Significance of primary stability for osseointegration of dental implants. Clin Oral Implants Res 2006;17:244-250.

26. Orlik J, Zhurov A, Middleton J. On the secondary stability of coated cementless hip replacement: parameters that affected interface strength. Med Eng Phys 2003;25:825-831.

27. Tabassum A, Meijer GJ, Wolke JG, Jansen JA. Influence of the surgical technique and surface roughness on the primary stability of an implant in artificial bone with a density equivalent to maxillary bone: a laboratory study. Clin Oral Implants Res 2009:20:327-332

28. Tabassum A, Meijer GJ, Wolke JG, Jansen JA. Influence of surgical technique and surface roughness on the primary stability of an implant in artificial bone with different cortical thickness: a laboratory study. Clin Oral Implants Res 2010;21:213-220.

29. Kasten P, Neubrech C, Raiss $\mathbf{P}$, et al. Humeral head resurfacing in central bone defects: in vitro stability of different implants with increasing defect size. J Orthop Res 2012;30:1285-1289. 